\title{
Risks factors of mechanical ventilation in acute traumatic cervical spinal cord injured patients
}

\author{
Antonio Montoto-Marqués $\mathbb{D}^{1,2} \cdot$ Natalia Trillo-Dono ${ }^{1} \cdot$ María Elena Ferreiro-Velasco ${ }^{1}$. \\ Sebastián Salvador -de la Barrera ${ }^{1} \cdot$ Antonio Rodriguez-Sotillo $^{1} \cdot$ Mónica Mourelo-Fariña $^{3} \cdot$ Rita Galeiras-Vázquez $^{1}$. \\ Rosa Meijide-Failde ${ }^{4}$
}

Received: 20 June 2017 / Revised: 14 August 2017 / Accepted: 15 August 2017 / Published online: 23 October 2017

(c) International Spinal Cord Society 2018

\begin{abstract}
Study design Descriptive retrospective study.

Objectives To analyze risk factors associated with mechanical ventilation (MV) in cases of acute traumatic Cervical Spinal Cord Injury (tCSCI).

Setting Unidad de Lesionados Medulares, Complejo Hospitalario Universitario A Coruña, in Galicia (Spain).

Methods The study included patients with tCSCI who were hospitalized between January 2010 and December 2014. The following variables were analyzed: age, gender, etiology, neurological level, ASIA (American Spinal Injury Association) grade, associated injuries, injury severity score (ISS), ASIA motor score (AMS) at admission and mortality.

Results A total of 146 patients met the study's inclusion criteria. The majority were men (74.7\%) with mean age of 62.6 (s.d. \pm 18.8 ) years. Sixty patients $(41.1 \%)$ required MV. Mean age of ventilated vs. non-ventilated patients was 57.3 vs. 65.7. Men were more likely to require MV than women, ASIA grades A and B were also more likely to need MV than grades C and $\mathrm{D}$, as well as patients with associated injuries. The AMS of patients receiving MV was lower than that of those who did not require MV (20.1 vs. 54.3). Moreover, the ISS was higher in patients receiving MV (31.2 vs. 13.4). An AMS $\leq 37$ and an ISS $\geq 13$ increased the risk of requiring MV by a factor of 11.98 and 7.28 , respectively.

Conclusions Isolated factors associated with a greater risk of MV in tCSCI were: age, gender, ASIA grade, ISS and AMS. However, the only factor with a significant discriminatory ability to determine the need for MV was the AMS at admission.
\end{abstract}

\section{Introduction}

In recent years we have witnessed a change in the incidence and characteristics of traumatic cervical spinal cord injuries (tCSCI). Owing to the advances in the treatment of spinal

$\triangle$ Antonio Montoto-Marqués

antonio.montoto.marques@sergas.es

1 Unidad de Lesionados Medulares, Complexo Hospitalario Universitario A Coruña (CHUAC), A Coruña, Spain

2 Departamento de Medicina, Universidade da Coruña, A Coruña, Spain

3 Unidad de Cuidados Intensivos, Complexo Hospitalario Universitario A Coruña (CHUAC), A Coruña, Spain

4 Departamento de Medicina, Universidade da Coruña, INIBIC, Complexo Hospitalario Universitario de A Coruña (CHUAC), A Coruña, Spain cord injuries and the change in their etiology; more casual falls in elderly patients resulting in incomplete tetraplegia, we have observed an increase in the incidence of incomplete tCSCI [1]. Furthermore, there has been an increase in the number of cases of high level CSCI, which results in a greater percentage of ventilator-dependent patients. Thus, according to DeVivo, the incidence of C1-C4 injuries in the USA has increased from 12.3 to $27.2 \%$, and the number of ventilator-dependent SCI patients has increased from $1.5 \%$ in the 1970 s to $5.4 \%$ in the 2000 s [2].

CSCI is frequently associated with respiratory failure within the first days after its onset, with the consequent need for mechanical ventilation [3-5]. This respiratory failure is primarily caused by the paralysis of the respiratory muscles, which leads to a decrease in the patient's inspiratory capacity, the formation of atelectasis and the retention of secretions owing to the patients' ineffective coughing [6]. In addition, the autonomic dysfunction resulting from the spinal cord injury causes bronchospasm, increased 
secretions and pulmonary edema [4]. All these circumstances lead to the need for the premature, and ideally programmed, use of $\mathrm{MV}$ in order to avoid the complications resulting from the emergency procedure, given that emergency intubation may increase the risk of neurological damage due to the poor handling of the cervical spine or to hypoxia [7].

Traditionally, the need for invasive ventilatory assistance has been associated with the level and extent of the spinal cord injury [3]. Hence, patients with complete spinal cord injuries according to the ASIA classification [8], and with injuries above neurological level $\mathrm{C} 5$, would have an impaired diaphragmatic function and would require immediate ventilatory support $[3,9]$. In contrast, patients with incomplete spinal cord injuries affecting neurological level $\mathrm{C} 4$ or below, have a lower risk of requiring $\mathrm{MV}$ $[5,10]$. However, there is a lack of evidence in the available literature with regard to the specific factors related to the need for MV [11].

To identify those risk factors could help clinicians to apply mechanical ventilation in a programmed and premature manner to the riskier patients and so to reduce the incidence of medical complications [12]. Thus, the objective of our study, beyond developing a prediction model, is to analyze those risk factors associated with the need for invasive ventilatory assistance in patients with tCSCI.

\section{Methods}

\section{Analyzed population}

We conducted a retrospective descriptive study of patients admitted to the Unidad de Lesionados Medulares, Complejo Hospitalario Universitario de A Coruña (Spain) between January 2010 and December 2014. This center, which is located in the north west of Spain, is a reference center for the treatment of spinal cord injuries and serves a population of 2,750,000 inhabitants.

The study's inclusion criteria were: patients with acute traumatic cervical spinal cord injury admitted to our center within the first week after injury, age $\geq 18$ years, and information on the ASIA exam at admission. A total of 278 patients with a traumatic spinal cord injury were admitted to our Unit during the study period. Of these, only 146 patients met our study's inclusion criteria.

\section{Analyzed data}

Relevant data were extracted from the admissions registry of the Unit and from the patients' electronic health records. The following variables were analyzed: age, gender, etiology of the injury, neurological level, extent of the injury according to ASIA impairment scale, associated injuries, injury severity score (ISS), ASIA motor score on admission to the Unit and mortality.

International Standards for the neurological classification of spinal cord injuries according to the ASIA, revised in 2011, were used to assess the affected neurological level and the extent of the spinal cord injury [8]. For the ASIA analysis we grouped patients into two groups: complete motor injuries (grades A and B) and incomplete motor injuries (grades $\mathrm{C}$ and $\mathrm{D}$ ).

The following were considered associated injuries: head trauma, facial trauma, chest trauma, other vertebral fractures, abdominal or pelvic trauma, limb fractures and other injuries. Furthermore, we used the Injury Severity Score (ISS) to assess the severity of the injury. The ISS is a numerical scale used to assess an anatomical injury, and it is frequently used in the assessment of polytraumatized patients. It assesses the respiratory, cardiovascular, nervous, general and external systems, as well as the abdomen-pelvis and the limbs-pelvic bone. The ISS is calculated by summing the square of the 3 variables with the highest score in each of the most severely affected systems, the maximum score being 75 . A score $\geq 25$ is indicative of severe trauma to another region in addition to the spine [13].

\section{Statistical analysis}

Software SPSS 19.0 was used to analyze the study data. The data were expressed as means $+/-$ standard deviation or percentages. Qualitative variables were analyzed with the Chi-square test or Fisher's test. T-student's test was used to analyze quantitative variables. A p-value $<0.05$ was considered to be statistically significant. We first carried out a univariate analysis to determine which variables were statistically significant in terms of the risk of requiring $\mathrm{MV}$, and we later analyzed these variables through logistic regression. We also used ROC (Receiver Operating Characteristics) curves to measure the discriminatory capacity of quantitative variables AMS and ISS to predict the risk of the need for mechanical ventilation, obtaining an optimal cutoff by calculating the Youden index (=max sensitivity-specificity-1). The area under the curve (AUC) measures the discriminatory capacity of the model considering scores lower than 0.75 have a poor predictive discrimination and from 0.76 to 1.0 to be indicative of a good/excellent predictive discrimination.

\section{Ethical and legal aspects}

The study and analysis of data were approved by the Technical Secretariat of the Autonomic Research Ethics Committee of Galicia, General Secretariat (registry code 2015/155). 


\section{Results}

During the study period, a total of 278 patients with an acute traumatic spinal cord injury were admitted to the Spinal Cord Injury Unit, of whom 84 and 48 patients were excluded from the study due to dorsal and lumbosacral spinal cord injury respectively. A total of 146 patients met the inclusion criteria. The majority of patients were men $(74.7 \%)$ with a mean sample age of 62.6 (s.d. \pm 18.8 ) years. The etiology of the most frequent type of injury was falls $(72.8 \%)$, followed by traffic accidents (17.7\%) and other traumatic causes, which included, among others, swimming dives (3.4\%), falls by suicide attempt $(4.1 \%)$ and occupational accidents $(2 \%)$. The SCI was incomplete motor in $64.5 \%$ of patients, without associated lesions in $61 \%$ of the cases. The most commonly affected neurological level was C1-C4 (60\%).

In 25 patients the AMS was unknown, the main reason being sedation of the patient in acute phase. The mean AMS was 42.9 (s.d. \pm 30.9 ) and the mean ISS was 20.7 (s.d. \pm 18.79). A total of $51.4 \%$ of the patients had to be admitted to the Intensive Care Unit (ICU), with the global mortality rate being of $16.4 \%$ (Table 1).

Of all patients included in the study, 60 (41.1\%) required MV. The mean age of these patients requiring MV was significantly lower than the global mean $[57.3$ (s.d. \pm 18.2 ) vs. 65.7 (s.d. \pm 18.6 ) years]. The proportion of men that required MV was higher than women (45.9 vs. 27\%). Moreover, patients with a SCI with an ASIA grade A or B were more likely to require $\mathrm{MV}$ compared to those with an ASIA grade C or D (71.4 vs. 27.1\%). Also, patients with an associated injury were also more likely to require MV than those without associated injuries (52.6 vs. 33.7\%) (Table 2).

The mean AMS of patients receiving mechanical ventilation was 20.1 (s.d. \pm 20.9 ), which is a much lower figure than that obtained for patients who had not required MV [54.3 (s.d. \pm 28.8 )] and for our whole sample [42.9(s.d. \pm 30.9)]. As for ISS, the mean score obtained for patients who had received MV was greater than that obtained for those who hadn't received it [31.2 (s.d. \pm 19.2$)]$ vs. [13.4 (s.d. \pm 14.3)] and that of the global sample [20.7 (s.d. \pm 18.7$)]$. All these results were statistically significant $(p<0.05)$ (Tables 1 and 2).

With regard to the neurological level, the percentage of mechanical ventilation was similar among the established levels (C1-C4: $41.7 \%$ and C5-C8: 33.9\%), thus indicating that the neurological level is not a significant predictive factor of the risk of requiring MV in this cohort $(p=0.357)$ (Table 2).

The percentage of deaths was higher in the group of patients who had received mechanical ventilation compared to those who hadn't (58.3 vs. $37.7 \%$ ). However, this difference in the mortality of both groups was not statistically significant $(p>0.05)$ (Table 2).
When analyzing the variables that had been significant in the univariate analysis through logistic regression, we found that the only statistically significant factor for predicting the need for invasive mechanical ventilation in our study was the AMS $(p<0.001)$ (Table 3$)$.

Furthermore, we tried to measure the discriminatory ability of quantitative variables AMS and ISS to predict the risk of requiring mechanical ventilation, using the ROC curves. We saw that for an AMS $\leq 37$, the risk of requiring MV increased by a factor of 11.98. Thus, in our study, $56.7 \%$ of patients with an AMS $\leq 37$ required MV compared to only $9.8 \%$ of those with an AMS $>37$ (Fig. 1, Table 4).

Table 1 Variables studied and their frequency in the global sample

\begin{tabular}{|c|c|c|}
\hline \multirow[t]{2}{*}{ Variables } & \multicolumn{2}{|c|}{ Frecuency } \\
\hline & $\%$ & $\mathrm{n}$ \\
\hline \multicolumn{3}{|l|}{ Gender } \\
\hline Male & 74.7 & 109 \\
\hline Female & 25.3 & 37 \\
\hline $\begin{array}{l}\text { Mean age } \pm s \text {. } \\
\text { d. }\end{array}$ & $\begin{array}{l}62.6 \pm \\
18.8\end{array}$ & \\
\hline \multicolumn{3}{|l|}{ Etiology } \\
\hline Falls & 72.8 & 107 \\
\hline $\begin{array}{c}\text { Traffic } \\
\text { accidents }\end{array}$ & 17.7 & 26 \\
\hline $\begin{array}{l}\text { Other } \\
\text { traumatic } \\
\text { causes }\end{array}$ & 9.5 & 13 \\
\hline \multicolumn{3}{|l|}{ ASIA } \\
\hline A, B & 35.5 & 49 \\
\hline C, D & 64.5 & 89 \\
\hline Unknown & & 8 \\
\hline \multicolumn{3}{|c|}{ Associated injuries } \\
\hline Yes & 39 & 57 \\
\hline No & 61 & 89 \\
\hline \multicolumn{3}{|c|}{ Neurological level } \\
\hline $\mathrm{C} 1-\mathrm{C} 4$ & 60 & 88 \\
\hline $\mathrm{C} 5-\mathrm{C} 8$ & 40 & 58 \\
\hline $\begin{array}{l}\text { AMS at } \\
\text { admission } \pm \mathrm{s} \text {. } \\
\text { d. }\end{array}$ & $\begin{array}{l}42.9 \pm \\
30.9\end{array}$ & \\
\hline ISS \pm s.d. & $\begin{array}{l}20.7 \pm \\
18.7\end{array}$ & \\
\hline \multicolumn{3}{|c|}{ Admission in ICU } \\
\hline Yes & 51.4 & 75 \\
\hline No & 48.6 & 71 \\
\hline \multicolumn{3}{|l|}{ Exitus } \\
\hline Yes & 16.4 & 24 \\
\hline No & 83.6 & 122 \\
\hline
\end{tabular}

s.d., Standard Deviation; ASIA, American Spinal Injury Association; $A M S$, ASIA motor score; ISS, injury severity score; $I C U$, Intensive Unit Care 
Table 2 Variables studied in relationship to mechanical ventilation

\begin{tabular}{|c|c|c|c|}
\hline & \multicolumn{2}{|c|}{ Mechanical ventilation (\%) } & \multirow[t]{2}{*}{$P$-value } \\
\hline & Yes & No & \\
\hline \multicolumn{4}{|l|}{ Gender } \\
\hline Male & 45.9 & 54.1 & $p=0.04$ \\
\hline Female & 27 & 73 & \\
\hline Mean age \pm s.d. & $57.3 \pm 18.2$ & $65.7 \pm 18.6$ & $p=0.01$ \\
\hline \multicolumn{4}{|l|}{ Etiology } \\
\hline Falls & 32.6 & 67.4 & $p=0.194$ \\
\hline Traffic accidents & 57.1 & 42.9 & \\
\hline Other traumatic causes & 41.7 & 58.3 & \\
\hline \multicolumn{4}{|l|}{ ASIA grade } \\
\hline A, B & 71.4 & 28.6 & $p<0.001$ \\
\hline $\mathrm{C}, \mathrm{D}$ & 27.1 & 72.9 & \\
\hline \multicolumn{4}{|l|}{ Associated injuries } \\
\hline Yes & 52.6 & 47.4 & \\
\hline No & 33.7 & 66.3 & $p=0.023$ \\
\hline \multicolumn{4}{|l|}{ Neurological level } \\
\hline $\mathrm{C} 1-\mathrm{C} 4$ & 41.7 & 58.3 & $p=0.357$ \\
\hline $\mathrm{C} 5-\mathrm{C} 8$ & 33.9 & 66.1 & \\
\hline AMS at admission \pm s.d & $20.1 \pm 20.9$ & $54.3 \pm 28.8$ & $p<0.001$ \\
\hline ISS & $31.2 \pm 19.2$ & $13.4 \pm 14.3$ & $p<0.001$ \\
\hline \multicolumn{4}{|l|}{ Exitus } \\
\hline Yes & 58.3 & 41.7 & $p=0.06$ \\
\hline No & 37.7 & 62.3 & \\
\hline
\end{tabular}

s.d., Standard Deviation; ASIA, American Spinal Injury Association; $A M S$, ASIA motor score; ISS, injury severity score

Table 3 Variables included in the logistic regression

\begin{tabular}{lllll}
\hline & $P$-value & $\operatorname{Exp}(\mathbf{B})$ & \multicolumn{2}{c}{$\mathbf{9 5 \%}$ CI for Exp (B) } \\
\cline { 3 - 5 } & & & Inferior & Superior \\
\hline Gender & 0.106 & 2.864 & 0.800 & 10.257 \\
Age & 0.339 & 0.987 & 0.960 & 1.014 \\
AMS & 0.000 & 0.951 & 0.927 & 0.975 \\
ISS & 0.074 & 1.031 & 0.997 & 1.067 \\
Associated injuries & 0.971 & 0.982 & 0.355 & 2.713 \\
ASIA grade & 0.291 & 0.507 & 0.143 & 1.791 \\
\hline
\end{tabular}

$C I$, confidence interval; $A M S$, ASIA motor score; ISS, injury severity score

As for the ISS, the cutoff point with the greatest sensitivity-specificity ratio in the ROC curve was 13 . Thus, in our study, patients with an ISS $\geq 13$ on admission to the Unit had a 7.28-times higher risk of requiring $\mathrm{MV}$, in other words, $58.8 \%$ of patients with an ISS $\geq 13$ on their admission to the Unit required MV vs. only $16.4 \%$ of those with an ISS $<13$ (Fig. 2, Table 4).

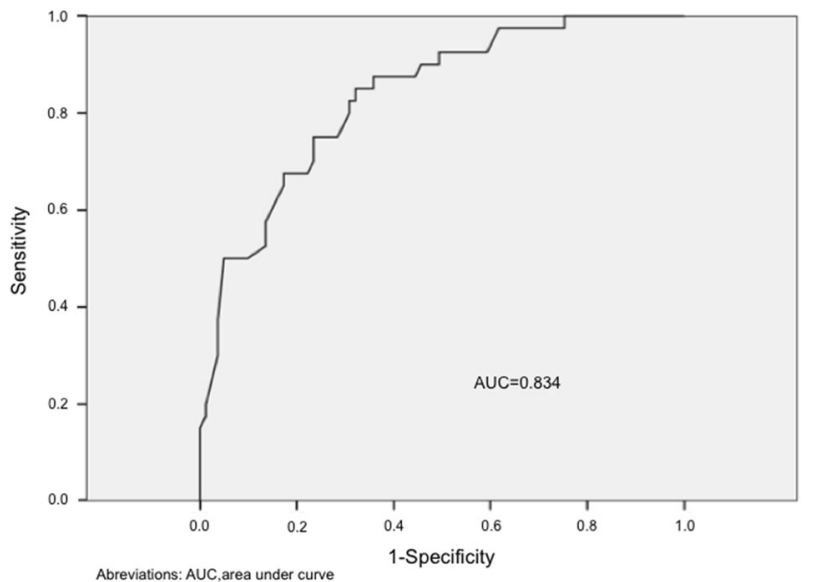

Fig. 1 ROC curve for ASIA motor score at admission

Table 4 Relationship between ASIA motor score at admission and Injury Severity Score and the risk of mechanical ventilation

\begin{tabular}{|c|c|c|c|c|c|}
\hline & \multicolumn{2}{|l|}{ MV } & \multirow[t]{2}{*}{ OR } & \multicolumn{2}{|l|}{$95 \%$ CI } \\
\hline & $\begin{array}{l}\text { No } \\
\text { n (\%) }\end{array}$ & $\begin{array}{l}\text { Yes } \\
\text { n }(\%)\end{array}$ & & inferior & superior \\
\hline AMS > 37 & $55(90.2 \%)$ & $6(9.8 \%)$ & & & \\
\hline $\mathrm{AMS} \leq 37$ & $26(43.3 \%)$ & $34(56.7 \%)$ & $11.98 *$ & 4.47 & 32.10 \\
\hline ISS $<13$ & $51(83.6 \%)$ & $10(16.4 \%)$ & & & \\
\hline ISS $\geq 13$ & $35(41.2 \%)$ & $50(58.8 \%)$ & $7.28^{*}$ & 3.26 & 16.27 \\
\hline
\end{tabular}

$M V$, mechanical ventilation; $O R$, Odds Ratio; $C I$, confidence interval; $A M S$, ASIA motor score; ISS, injury severity score

$* p<0.001$

\section{Discussion}

Cervical spinal cord injuries are frequently associated with respiratory failure within the first few days of evolution, with the consequent need for MV. In our study, $41.1 \%$ of patients with an acute cervical spinal cord injury required MV. Other authors have published higher percentages: Claxton et al. 57\%, Jones et al. 57.6\% [14, 15].

Traditionally, the need for invasive ventilatory assistance has been associated with the level and extent of the spinal cord injury [3, 9, 15]. In our study, a univariate analysis proved that the following factors were related to the need for MV: gender, age, ASIA grade, existence of associated injuries, AMS and ISS. We agree with other authors, such as Song et al. and Claxton et al. [11, 14], that the neurological level, the complete nature of the injury and the patient's age, are predictive factors of the need for MV, although, in our study, the difference was that lower age at injury was associated with higher risk of MV. Nevertheless, the age stratification implemented by some of these authors started as of the age of 40 years, whereas in our study we simply carried out a comparison of means. The greater risk 


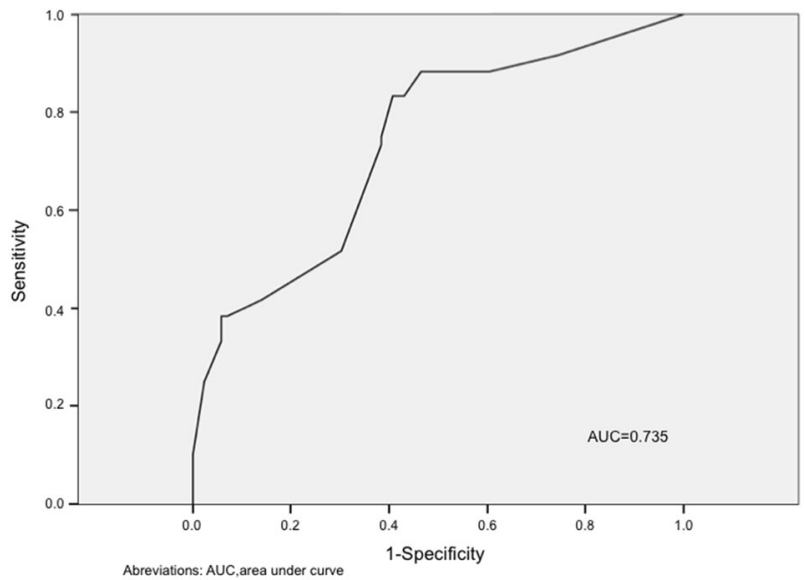

Fig. 2 ROC curve for Injury Severity Score

in the younger patients of our series may be explained by the severity of the traumatic injury (ISS 24.5 in patients aged $<60$ years vs. ISS 16.6 in patients aged $>60$ years). These results were similar to the Aarabi series, in which younger patients are at increased risk for respiratory complications, including respiratory failure [16].

In the initial analysis, the gender proved to be a significant factor, with the risk of requiring MV being higher in men, probably owing to the greater incidence of complete spinal cord injuries among male patients. However, in other studies analyzing this variable, sex did not seem to be a significant factor related to respiratory failure [7, 11].

As for the severity of the spinal cord injury, the available literature considered this factor to be directly related to the risk of respiratory failure, and, therefore, of the need for mechanical ventilation [17-19]. In our study, $73.8 \%$ of patients with ASIA grade A required MV, which is a similar figure to that reported in other series (90\% Jones et al. 2015; 74\% Velmahos et al. 2003; 77.1\% Aarabi et al. 2012;) $[9,15,16]$. The spinal cord segments C3-C4-C5 are responsible for innervating the diaphragm, hence, patients with complete spinal cord injuries according to the ASIA classification and with neurological levels above $\mathrm{C} 4$, would have an impaired diaphragmatic function and would usually need immediate ventilatory support. Thus, traditionally, the affected neurological level in cases of complete CSCI has been considered a risk factor of the need for $\mathrm{MV}$ $[3,11,14,15,20]$. However, in our study, this level was not a predictive factor of the need for MV. This difference may be related to the fact that we studied both complete and incomplete spinal cord injuries, such as Huang et al., who obtained similar results to ours by comparing neurological levels above C5 [7].

Associated injuries are risk factors of the need for mechanical ventilation, a fact proven by the greater ISS in patients who required MV. In some studies, the existence of concomitant injuries to the SCI was associated with a greater risk of the need for a tracheostomy or of respiratory complications [4, 21]. For example, according to Jones et al. and to Branco et al. an ISS $\geq 25$ and $\geq 16$, respectively, in incomplete lesions, is a risk factor of the need for a tracheostomy [15, 22].

The ASIA motor score is related to the severity of the neurological injury, hence, it seems logical to think that the lower motor score on admission, the greater the risk of requiring ventilatory support. In our series, the AMS proved to be a significant risk factor of the need for MV, as those patients who received MV had a much lower AMS than those who did not require invasive ventilatory support. Furthermore, this factor proved to be the only significant variable in the logistic regression analysis. We did not find studies that directly correlated the AMS with the risk of needing MV, but we did find it described as a risk factor of the need for prolonged MV [12], of the onset of respiratory complications and of the need for a tracheostomy. In fact, according to Aarabi [16]: "an $A M S<25$ increases the risk of onset of respiratory complications by nine-fold compared to patients with a motor score $>50$ ". Similarly, in the series conducted by Leelapattana et al. [21], those patients who required a tracheostomy had an AMS of 22 vs. the AMS of 39 of those who did not need it.

\section{Study limitations}

Our study constitutes an observational retrospective study, therefore the information which allows us to determine the presence or absence of a condition may be missing on recorded inaccurately. Moreover, the study was designed to identify likely predictors, but not necessarily a causal relationship. The study is also limited by the relatively small amount of patients.

\section{Conclusions}

In our study, CSCI were associated with a high risk of requiring MV. Isolated factors associated with a greater risk of requiring mechanical ventilation in our population of cervical spinal cord injuries were: age, sex, ASIA grade, ISS and AMS. However, the only factor which, owing to its greater discriminatory capacity, can assist in determining the need for elective mechanical ventilation in these patients, is the AMS. This suggests that preserving motor function might decrease the risk of MV in cases of cervical spinal cord injury.

\section{Data archiving}

All relevant data are within this manuscript and raw data are archived by the authors. 


\section{Compliance with ethical standards}

Conflict of interest The authors declare that they have no competing interests.

\section{References}

1. McCaughey EJ, Purcell M, McLean AN, Fraser MH, Bewick A, Borotkanics RJ, et al. Changing demographics of spinal cord injury over a 20-year period: a longitudinal population-based study in Scotland. Spinal Cord. 2016;54(4):270-6.

2. Devivo MJ. Epidemiology of traumatic spinal cord injury: trends and future implications. Spinal Cord. 2012;50(5):365-72.

3. Como JJ, Sutton ER, McCunn M, Dutton RP, Johnson SB, Aarabi $\mathrm{B}$, et al. Characterizing the need for mechanical ventilation following cervical spinal cord injury with neurologic deficit. J Trauma. 2005;59(4):912-6. discussion 6

4. Berlly M, Shem K. Respiratory management during the first five days after spinal cord injury. J Spinal Cord Med. 2007;30 (4):309-18.

5. Jackson $\mathrm{AB}$, Groomes $\mathrm{TE}$. Incidence of respiratory complications following spinal cord injury. Arch Phys Med Rehabil. 1994;75 (3):270-5.

6. Dicpinigaitis PV, Spungen AM, Bauman WA, Absgarten A, Almenoff PL. Bronchial hyperresponsiveness after cervical spinal cord injury. Chest.. 1994;105(4):1073-6.

7. Huang $\mathrm{YH}, \mathrm{Ou} \mathrm{CY}$. Magnetic resonance imaging predictors for respiratory failure after cervical spinal cord injury. Clin Neurol Neurosurg. 2014;126:30-4.

8. Kirshblum SC, Burns SP, Biering-Sorensen F, Donovan W, Graves DE, Jha A, et al. International standards for neurological classification of spinal cord injury (revised 2011). J Spinal Cord Med. 2011;34(6):535-46.

9. Velmahos GC, Toutouzas K, Chan L, Tillou A, Rhee P, Murray J, et al. Intubation after cervical spinal cord injury: to be done selectively or routinely? Am Surg. 2003;69(10):891-4.

10. Schmitt J, Midha M, McKenzie N. Medical complications of spinal cord disease. Neurol Clin. 1991;9(3):779-95.

11. Song J, Shao J, Qi HH, Song DW, Zhu W. Risk factors for respiratory failure with tetraplegia after acute traumatic cervical spinal cord injury. Eur Rev Med Pharmacol Sci. 2015; 19(1):9-14.

12. Roquilly A, Seguin P, Mimoz O, Feuillet F, Rosenczweig E, Chevalier F, et al. Risk factors for prolonged duration of mechanical ventilation in acute traumatic tetraplegic patients--a retrospective cohort study. J Crit Care. 2014;29(2):313. e7-13

13. Copes WS, Champion HR, Sacco WJ, Lawnick MM, Keast SL, Bain LW. The Injury Severity Score revisited. J Trauma. 1988;28 (1):69-77.

14. Claxton AR, Wong DT, Chung F, Fehlings MG. Predictors of hospital mortality and mechanical ventilation in patients with cervical spinal cord injury. Can J Anaesth. 1998;45(2):144-9.

15. Jones TS, Burlew CC, Johnson JL, Jones E, Kornblith LZ, Biffl WL, et al. Predictors of the necessity for early tracheostomy in patients with acute cervical spinal cord injury: a 15-year experience. Am J Surg. 2015;209(2):363-8.

16. Aarabi B, Harrop JS, Tator CH, Alexander M, Dettori JR, Grossman RG, et al. Predictors of pulmonary complications in blunt traumatic spinal cord injury. J Neurosurg Spine. 2012;17(1 Suppl):38-45.

17. Stiller K, Simionato R, Rice K, Hall B. The effect of intermittent positive pressure breathing on lung volumes in acute quadriparesis. Paraplegia. 1992;30(2):121-6.

18. Linn WS, Adkins RH, Gong H, Waters RL. Pulmonary function in chronic spinal cord injury: a cross-sectional survey of 222 southern California adult outpatients. Arch Phys Med Rehabil. 2000;81(6):757-63.

19. Galeiras Vázquez R, Rascado Sedes P, Mourelo Fariña M, Montoto Marqués A, Ferreiro Velasco ME. Respiratory management in the patient with spinal cord injury. Biomed Res Int. 2013;2013:168757.

20. Arora S, Flower O, Murray NP, Lee BB. Respiratory care of patients with cervical spinal cord injury: a review. Crit Care Resusc. 2012;14(1):64-73.

21. Leelapattana P, Fleming JC, Gurr KR, Bailey SI, Parry N, Bailey CS. Predicting the need for tracheostomy in patients with cervical spinal cord injury. J Trauma Acute Care Surg. 2012;73 (4):880-4.

22. Branco BC, Plurad D, Green DJ, Inaba K, Lam L, Cestero R, et al. Incidence and clinical predictors for tracheostomy after cervical spinal cord injury: a National Trauma Databank review. J Trauma. 2011;70(1):111-5. 